\title{
Fabrication and Characterization of PCBM:P3HT Bulk Heterojunction Solar Cells Doped with Germanium Phthalocyanine or Germanium Naphthalocyanine
}

\author{
Kazumi Yoshida $^{1}$, Takeo Oku ${ }^{1 *}$, Atsushi Suzuki ${ }^{1}$, Tsuyoshi Akiyama ${ }^{1}$, Yasuhiro Yamasaki ${ }^{2}$ \\ ${ }^{1}$ Department of Materials Science, The University of Shiga Prefecture, Shiga, Japan; ${ }^{2}$ Department of New Business, Orient Chemi- \\ cal Industries Co. Ltd., Osaka, Japan. \\ Email: *oku@mat.usp.ac.jp
}

Received January $31^{\text {st }}, 2013$; revised March $2^{\text {nd }}, 2013$; accepted April $5^{\text {th }}, 2013$

Copyright (C) 2013 Kazumi Yoshida et al. This is an open access article distributed under the Creative Commons Attribution License, which permits unrestricted use, distribution, and reproduction in any medium, provided the original work is properly cited.

\begin{abstract}
[6,6]-phenyl $\mathrm{C}_{61}$-butyric acid methyl ester: poly (3-hexylthiophene) bulk heterojunction solar cells doped with germanium phthalocyanine or germanium naphthalocyanine were fabricated and characterized. Photovoltaic properties of the solar cells with inverted structures were investigated by optical absorption, current density-voltage characteristic and incident photon to current conversion efficiency. These germanium phthalocyanine and germanium naphthalocyanine blended as the third component absorbed light with wavelength longer than $700 \mathrm{~nm}$. Morphology of solar cells was investigated by atomic force microscopy, and energy levels of the solar cells were discussed for power conversion efficiency.
\end{abstract}

Keywords: Organic Solar Cell; Inverted Structure; Phthalocyanine; Germanium; P3HT; PCBM

\section{Introduction}

Solar cells are expected to solve problems of environmental pollution and exhaustion of fossil fuel, and development and practical use of the solar energy are needed. Organic solar cells have an advantage for renewable energy resources due to their low cost, light weight and flexible, and they are fabricated at low temperatures by spin-coating and printing methods [1-3]. Recently, polymer solar cells using poly (3-hexylthiophene) (P3HT) and [6,6]-phenyl $\mathrm{C}_{61}$-butyric acid methyl ester (PCBM) have been investigated, and the conversion efficiency of $\sim 5 \%$ was obtained [4-6].

Metal phthalocyanines (MPc) and naphthalocyanines $(\mathrm{MNc})$ are group of small molecular materials with Qband absorption in the red to near-infraded range, and they have high optical, chemical stability and photovoltaic property. Therefore, they are used for donor materials of organic solar cells. The heterojunction solar cells using copper phthalocyanine and fullerene have been fabricated by evaporation method, and its power conversion efficiency was $\sim 3 \%$ [7]. The characteristics such as electronic conductivity, crystalline structure and

"Corresponding author. absorption range change by changing a central metal [8-11].

The organic solar cells such as using P3HT and PCBM exhibit incident good photon to current conversion efficiency (IPCE) and fill factor (FF). The device performance of such polymer solar cells can be enhanced by preparation condition such as annealing temperature, concentration and film thickness [12-15].

Addition of the third components such as phthalocyanine, naphthalocyanine and low bandgap polymers, is expected to absorb light with wavelength that the P3HT and PCBM cannot collect. Especially, phthalocyanines absorb near-infrared region of light, and are used widely. MPc and MNc are dissolved into organic solvents. Application to the device process using a spin-coating method is possible for the solubilization.

The purpose of the present work is to fabricate and characterize bulk heterojunction polymer solar cells with inverted structures using PCBM, P3HT and soluble tetrakis(tert-butyl)[bis(trihexylsiloxy)germanium 2,3 phthalocanine] (GePc) or tetrakis(trimethylsilyl)[hydroxylgerumanium-2,3-naphthalocyanine] (GeNc). $\mathrm{GePc}$ and $\mathrm{GeNc}$ were added as the third component for PCBM: P3HT solar cells. Photovoltaic mechanism, the light in- 
Fabrication and Characterization of PCBM:P3HT Bulk Heterojunction Solar Cells

Doped with Germanium Phthalocyanine or Germanium Naphthalocyanine

duced charge separation and charge transfer of the solar cells with inverted structures ware discussed on the basis of light-induced current density-voltage (J-V) curves, IPCE and optical absorption. Surface structures of thin films were also investigated by atomic force microscopy (AFM), and an energy level diagram of the present solar cells was discussed for power conversion efficiency.

\section{Experimental Procedures}

Organic semiconductor materials used in present work are shown in Figure 1. Solar cells with an inverted structure were fabricated by a following process. Indium tin oxide (ITO) substrates (Xin Yan Technology, $\sim 10 \Omega / \square$ ) were cleaned by an ultrasonic bath with acetone and methanol, and were dried by nitrogen gas. The $\mathrm{TiO}_{\mathrm{X}}$ precursor solution was prepared from titanium isopropoxide (TTIP), 2-methoxyethanol and acetylacetone. TTIP $(0.46 \mathrm{ml})$ was added to 2-methoxyethanol $(2.5 \mathrm{ml})$ and acetylacetone $(0.61 \mathrm{ml})$. The $\mathrm{TiO}_{\mathrm{X}}$ precursor solution was spin-coated on the ITO substrate. After annealing at $140^{\circ} \mathrm{C}$ in air, an organic layer was prepared on a $\mathrm{TiO}_{\mathrm{X}}$ layer by spin-coating using a mixed solution of P3HT (Merck KGaA), PCBM (American Dye Source), GePc (Orient Chemical Industries) or GeNc (Orient Chemical Industries) in $1 \mathrm{ml}$ o-dichlorobenzene. The weight ratio of PCBM:P3HT(GePc or GeNc) was 15:10:1. Then, a PEDOT:PSS layer was spin-coated on the organic layer. Finally, gold $\mathrm{Au}$ ) metal contacts were evaporated as top electrodes. Layered structures of bulk heterojunction solar cells with the inverted structure were denoted as ITO/TiO ${ }_{\mathrm{X}} / \mathrm{PCBM}: \mathrm{P} 3 \mathrm{HT}(\mathrm{GePc}$ or GeNc)/PEDOT:PSS/ $\mathrm{Au}$, as shown in a schematic illustration of Figure 2. (a)

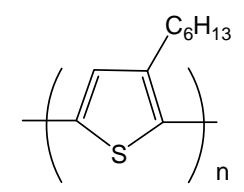

(c)

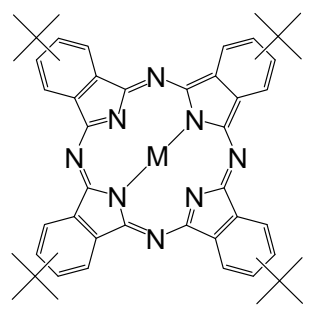

$\mathrm{M}=\mathrm{Ge}(\mathrm{OSiHEX} 3)_{2}$ (b)

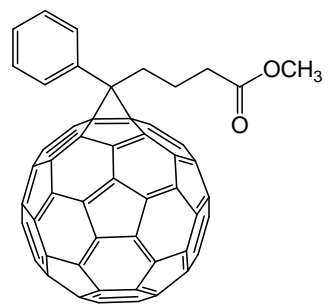

(d)

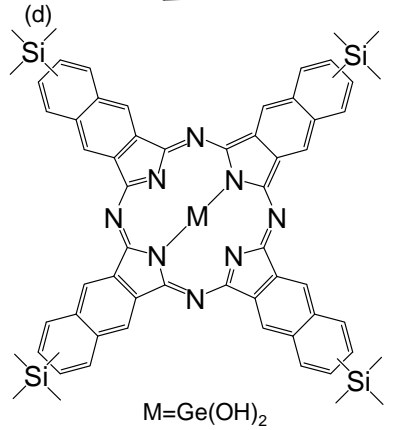

Figure 1. Molecular structures with (a) P3HT (b) PCBM, (c) GePc and (d) GeNc.
Current density-voltage (J-V) characteristics (Hokuto Denko, HSV-110) of the solar cells were measured both in the dark and under illumination at $100 \mathrm{~mW} / \mathrm{cm}^{2}$ by using an AM 1.5 solar simulator (San-ei Electric, XES301S). The solar cells were illuminated through the side of the ITO substrate, and the illuminated areas were 0.16 $\mathrm{cm}^{2}$. Optical absorption of the solar cells was investigated by means of ultraviolet-visible-near-infrared spectroscopy (Jasco, V-670ST). The photocurrent spectra were converted to IPCE spectra using a photocurrent spectrum of a calibrated Si-photodiode upon the same irradiation (Peccell Technologies, PEC-S20). The surface morphology of thin films was observed by AFM (SII Nano Technology, SPA400-AFM).

\section{Results and Discussion}

Figure 3 show absorption spectra of PCBM:P3HT $(\mathrm{GePc})$ and PCBM:P3HT(GeNc) thin films. The measurement region is in the range of 300 to $800 \mathrm{~nm}$. The optical absorption at $350 \mathrm{~nm}$ corresponds to that of Soret band of $\mathrm{GePc}$ and GeNc. Absorption in the range of 680 $720 \mathrm{~nm}$ and $700-760 \mathrm{~nm}$ correspond to Q-band for $\mathrm{GePc}$ and GeNc, respectively. Absorption at $\sim 400 \mathrm{~nm}$ is attributable to PCBM. The absorption wavelength of the

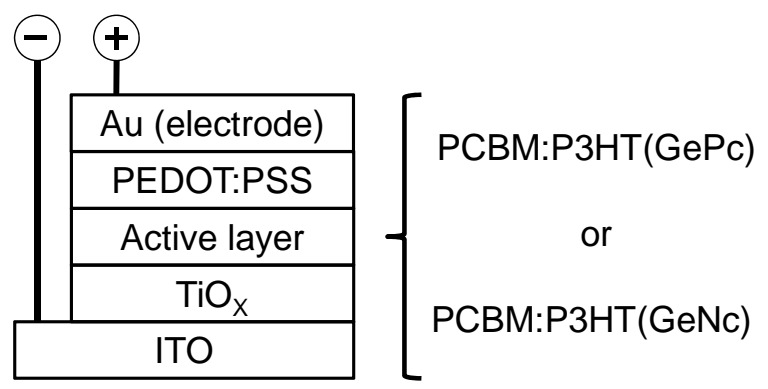

Figure 2. Schematic structure of the present solar cells.

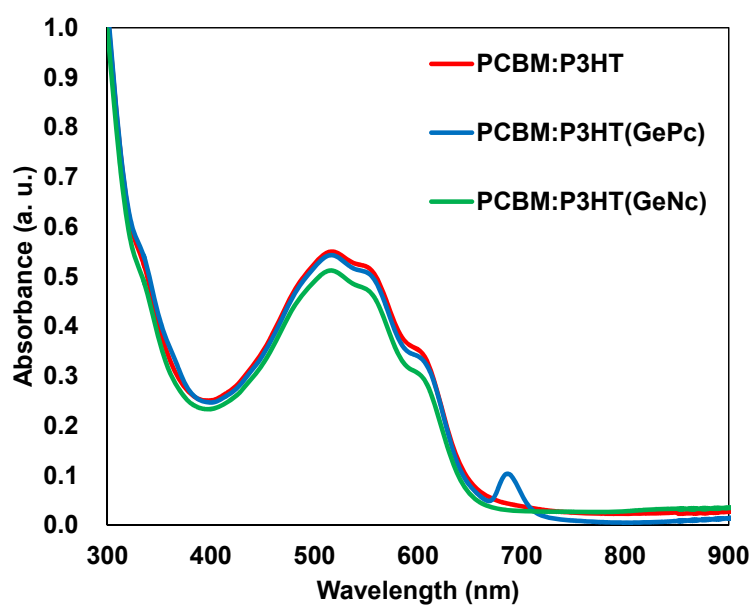

Figure 3. Optical absorption spectra of PCВM:P3HT(GePc) and PCBM:P3HT(GeNc) thin films. 
organic layer was able to be expanded by adding $\mathrm{GePc}$ or GeNc to PCBM:P3HT. Since the absorption was observed in the whole region, it is considered that the sunlight is efficiently absorbable.

Figure 4 show measured J-V characteristic curves of PCBM:P3HT(GePc) and PCBM:P3HT(GeNc) solar cells. Measured J-V characteristic parameters of solar cells under illumination are summarized in Table 1. Device performance of the solar cell doped with $\mathrm{GePc}$ or GeNc decreased.

IPCE spectra of solar cells are shown in Figure 5. An IPCE peak was observed around $700 \mathrm{~nm}$ for the solar cell with GePc. However, an IPCE peak was not observed in the solar cell with GeNc, which would be due to cohesion of $\mathrm{GeNc}$ in the organic layer. If $\mathrm{GeNc}$ aggregates exist in P3HT domain, charge separation does not occur. If the GeNc exists in PCBM domain, charge transfer

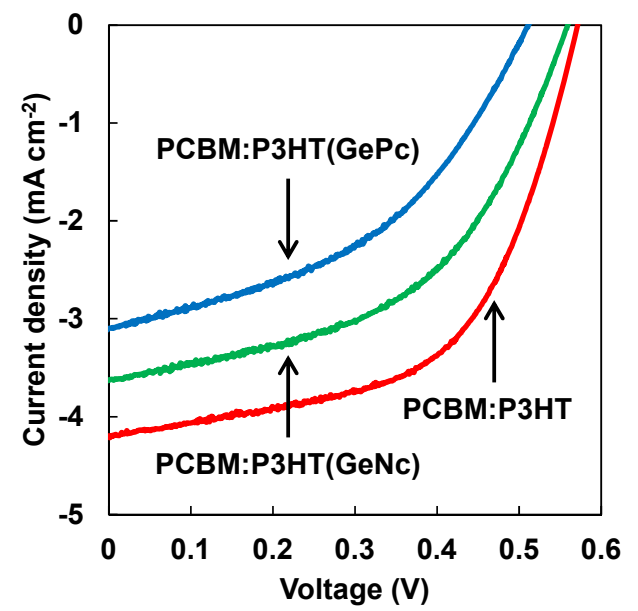

Figure 4. J-V characteristic of PCBM:P3HT(GePc) and PCBM:P3HT(GeNc) solar cells.

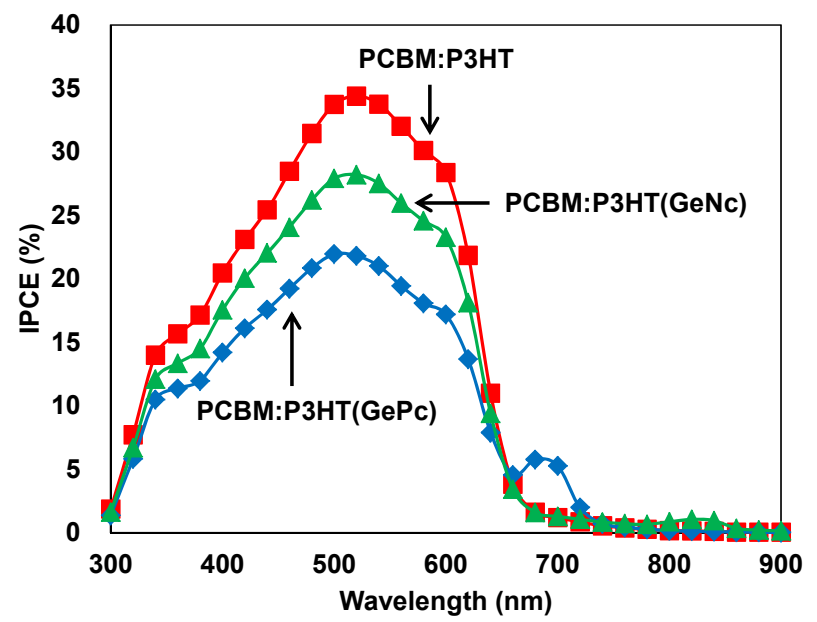

Figure 5. IPCE spectra of PCBM:P3HT(GePc) and PCBM: P3HT(GeNc) solar cells. does not occur. It was thought that the power conversion efficiency would be improved only when GeNc exists at the PCBM:P3HT interface. Since, a peak of IPCE for $\mathrm{GePc}$ was observed at $700 \mathrm{~nm}, \mathrm{GePc}$ would exists at the PCBM:P3HT interface. Since GePc has a perpendicular structure compared to $\mathrm{GeNc}$, it would be hard to condense.

Internal quantum efficiencies (IQE) of PCBM:P3HT, PCBM:P3HT(GePc) and PCBM:P3HT(GeNc) solar cells were calculated from the IPCE as shown in Figure 6. High IQEs are observed for the GePc and GeNc, which would be effective for photovoltaic properties.

Figures 7(a)-(c) show AFM images of PCBM:P3HT, PCBM:P3HT(GePc) and PCBM:P3HT(GeNc) thin films, respectively. The root-mean-square (RMS) surface roughness of PCBM:P3HT, PCBM:P3HT(GePc) and PCBM: $\mathrm{P} 3 \mathrm{HT}(\mathrm{GeNc})$ are $0.96,0.29$ and $0.96 \mathrm{~nm}$, respectively. The PCBM:P3HT(GePc) film indicated a rather smooth surface compared to those of PCBM:P3HT and PCBM: P3HT(GeNc).

An energy level diagram of PCBM:P3HT(GePc) solar cells is summarized as shown in Figure 8. Previously reported values were used for the energy levels of the

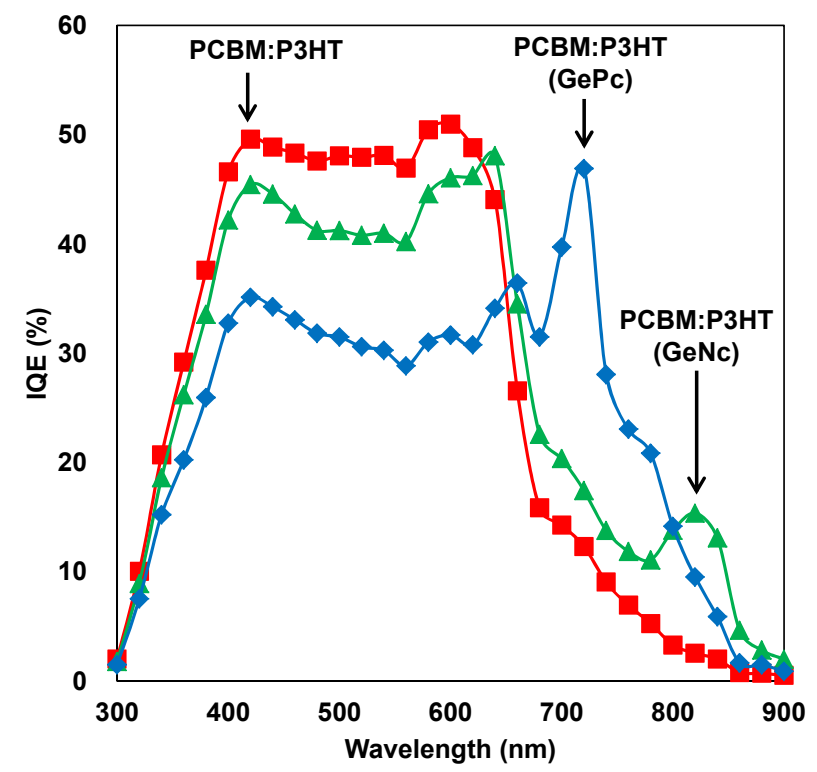

Figure 6. IQE spectra of PCBM:P3HT, PCBM:P3HT(GePc) and PCBM:P3HT(GeNc) solar cells.

Table 1. Experimental parameters of PCBM:P3HT(GePc or GeNc) solar cells.

\begin{tabular}{ccccc}
\hline Sample & $\mathrm{V}_{\mathrm{OC}}(\mathrm{V}) \mathrm{J}_{\mathrm{SC}}\left(\mathrm{mA} \cdot \mathrm{cm}^{-2}\right)$ & $\mathrm{FF}$ & $\eta(\%)$ \\
\hline PCBM:P3HT & 0.57 & 4.2 & 0.57 & 1.4 \\
PCBM:Р3HT(GePc) & 0.51 & 3.1 & 0.42 & 0.66 \\
PCBM:Р3HT(GeNc) & 0.56 & 3.6 & 0.50 & 1.0 \\
\hline
\end{tabular}




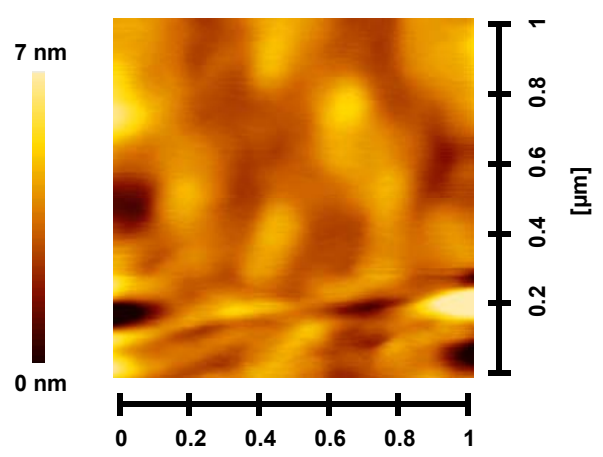

(a)

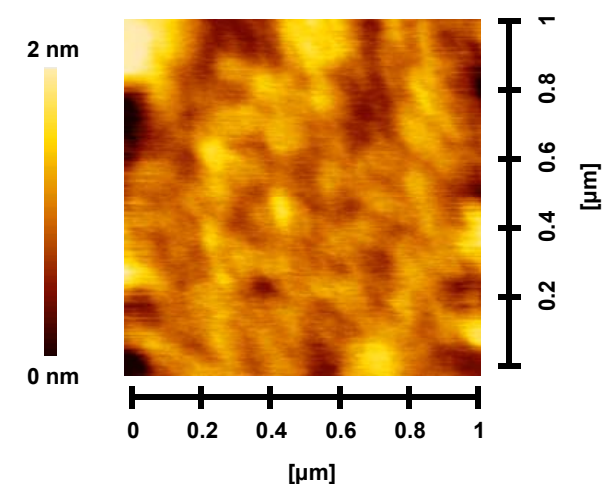

(b)

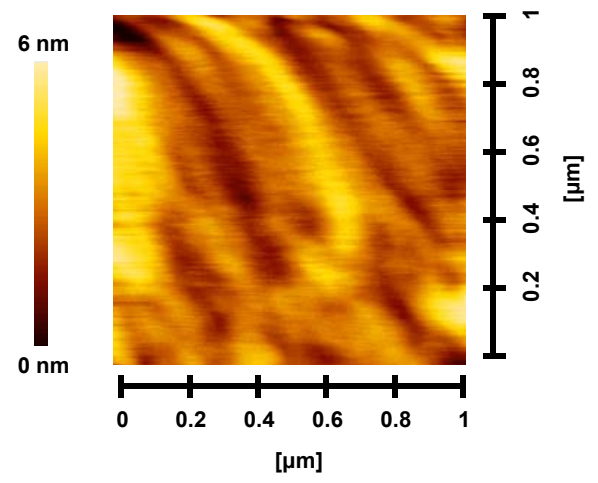

(c)

Figure 7. PCBM:P3HT (GePc) and (c) PCBM:P3HT(GeNc) thin films.

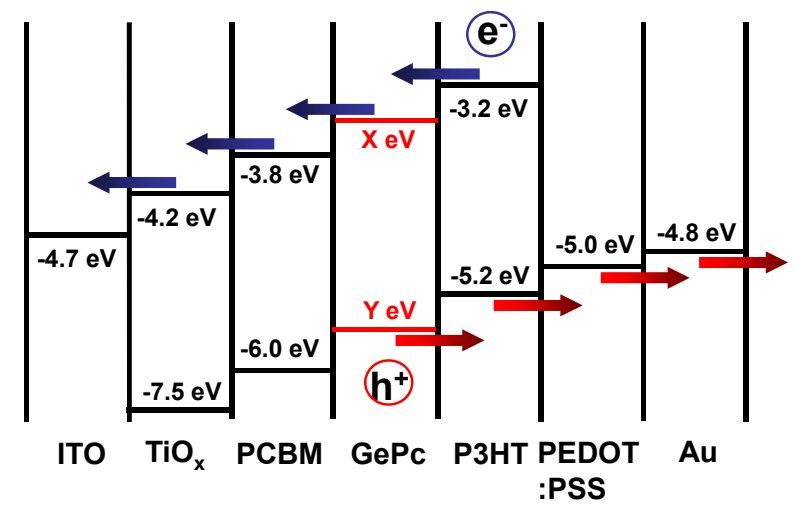

Figure 8. Energy level diagram of the present solar cell. figures by adjusting to the present work [16-20]. In the cell with the inverted structure, electrons are transported to an ITO substrate, and holes are transported to an $\mathrm{Au}$ electrode. In the present work, it is considered that GePc exists at the PCBM:P3HT interface. Electrons could be transported only when it is a value of LUMO for GePc $(\mathrm{X} \mathrm{eV})$ is $-3.7 \mathrm{eV} \leq \mathrm{X} \mathrm{eV} \leq-3.2 \mathrm{eV}$, and holes could be transported only when a value of HOMO for GePc (Y $\mathrm{eV}$ ) is $\mathrm{Y} \mathrm{eV} \leq-5.2 \mathrm{eV}$.

It is thought that control of HOMO and LUMO of the phthalocyanine is required for introduction to the polymer solar cells. Since a molecule exists in monomeric, a bulky molecular structure is required. Control of $\mathrm{HOMO}$ and LUMO becomes possible by exchange of a central metal and introduction of a substituent group.

\section{Conclusion}

PCBM:P3HT bulk heterojunction solar cells doped with GePc or GeNc were fabricated and characterized. The absorption wavelength was able to be expanded by adding GePc or GeNc to PCBM:P3HT. The RMS roughness of PCBM:P3HT $(\mathrm{GePc})$ film is the smaller than others. The decrease of conversion efficiency by the GePc or GeNc addition was considered from energy level diagram of the solar cells. IPCE spectra of the PCBM: P3HT(GePc) solar cell showed a peak around wavelengths of $700 \mathrm{~nm}$. Furthermore, IQE spectra of the PCBM: P3HT(GePc) and PCBM:P3HT(GeNc) solar cells showed high values at wavelengths longer than $700 \mathrm{~nm}$, which indicated that the enhancement of the solar cell performance would be possible by the GePc or GeNc addition.

\section{REFERENCES}

[1] M. Reyes-Reyes, K. Kim and D. L. Carroll, "High-Efficiency Photovoltaic Devices Based on Annealed Poly (3-Hexylthiophene) and 1-(3-Methoxycarbonyl)-propyl-1phenyl- $(6,6) \mathrm{C}_{61}$ Blends," Applied Physics Letters, Vol. 87, No. 8, 2005, 3p. doi:10.1063/1.2006986

[2] C. W. Tang, "Two-Layer Organic Photovoltaic Cell," Applied Physics Letters, Vol. 48, No. 2, 1986, pp. 183-185. doi:10.1063/1.96937

[3] P. Peumans, S. Uchida and S. R. Forrest, "Efficient Bulk Heterojunction Photovoltaic Cells Using Small-Molecular-Weight Organic Thin Films," Nature, Vol. 425, No. 11, 2003, pp. 158-162. doi:10.1038/nature01949

[4] F. Padinger, R. S. Rittberger and N. S. Saruciftci, "Effect of Postproduction Treatment on Plastic Solar Cells," Advanced Functional Materials, Vol. 13, No. 1, 2003, pp. 85-88. doi:10.1002/adfm.200390011

[5] W. Ma, C. Yang, X. Gong, K. Lee and A. J. Heeger, "Thermally Stable, Efficient Polymer Solar Cells with Nanoscale Control of the Interpenetrating Network Morphology," Advanced Functional Materials, Vol. 15, No. 
10, 2005, pp. 1617-1622. doi:10.1002/adfm.200500211

[6] J. A. Hauch, P. Schilinsky, S. A. Choulis, R. Childers, M. Biele and C. J. Brabec, "Flexible Organic P3HT:PCBM Bulk-Heterojunction Modules with More than 1 Year Outdoor Lifetime," Solar Energy Materials and Solar Cells, Vol. 92, No. 7, 2008, pp. 727-731. doi:10.1016/j.solmat.2008.01.004

[7] P. Peumans and S. R. Forrest, "Very-High-Efficiency Double-Heterostructure Copper Phthalocyanine/ $\mathrm{C}_{60}$ Photovoltaic Cells," Applied Physics Letters, Vol. 79, No. 1, 2001, pp. 126-128. doi:10.1063/1.1384001

[8] L. Li, Q. Tang, H. Li, W. Hu, X. Yang, Z. Shuai, Y. Liu and D. Zhu, "Organic Thin-Film Transistors of Phthalocyanines," Pure and Applied Chemistry, Vol. 80, No. 11, 2008, pp. 2231-2240. doi:10.1351/pac200880112231

[9] N. M. Bamsey, A. P. Yuen, A. M. Hor, R. Klenkler, J. S. Preston and R. O. Loutfy, "Integration of an M-Phthalocyanine Layer into Solution-Processed Organic Photovoltaic Cells for Improved Spectral Coverage," Solar Energy Materials and Solar Cells, Vol. 95, 2008, pp. 19701973. doi:10.1016/j.solmat.2011.01.042

[10] N. M. Bamsey, A. P. Yuen, A. M. Hor, R. Klenkler, J. S. Preston and R. O. Loutfy, "Heteromorphic Chloroindium Phthalocyanine Films for Improved Photovoltaic Performance," Solar Energy Materials and Solar Cells, Vol. 95, No. 5, 2011, pp. 2937-2940. doi:10.1016/j.solmat.2011.06.006

[11] D. Y. Kim, F. So and Y. Gao, "Aluminum Phthalocyaninechloride $/ \mathrm{C}_{60}$ Organic Photovoltaic Cells with High Open-Circuit Voltages," Solar Energy Materials and Solar Cells, Vol. 93, No. 9, 2009, pp. 1688-1691. doi:10.1016/j.solmat.2009.04.003

[12] Y. C. Huang, Y. C. Liao, S. S. Li, M. C. Wu, C. W. Chen and W. F. Su, "Study of the Effect of Annealing Process on the Performance of P3HT/PCBM Photovoltaic Devices Using Scanning-Probe Microscopy," Solar Energy Materials and Solar Cells, Vol. 93, No. 6-7, 2009, pp. 888-892. doi:10.1016/j.solmat.2008.10.027

[13] S. H. Jin, B. V. K. Naidu, H. S. Jeon, S. M. Park, J. S. Park, S. C. Kim, J. W. Lee and Y. S. Gal, "Optimization of Process Parameters for High-Efficiency Polymer Photovoltaic Devices Base on P3HT:PCBM System,"
Solar Energy Materials and Solar Cells, Vol. 91, No. 13, 2007, pp. 1187-1193. doi:10.1016/j.solmat.2007.04.001

[14] W. H. Baek, H. Yang, T. S. Yoon, C. J. Kang, H. H. Lee and Y. S. Kim, "Effect of P3HT:PCBM Concentration in Solvent on Performances of Organic Solar Cells," Solar Energy Materials and Solar Cells, Vol. 93, No. 8, 2009, pp. 1263-1267. doi:10.1016/j.solmat.2009.01.019

[15] G. Li, V. Shrotriya, Y. Yao and Y. Yang, "Investigation of Annealing Effects and Film Thickness Dependence of Polymer Solar Cells Based on Poly(3-Hexylthiophene)," Journal of Applied Physics, Vol. 98, No. 4, 2005, Article ID: 043704. doi:10.1063/1.2008386

[16] T. Oku, A. Takeda, A. Nagata, T. Noma, A. Suzuki and K. Kikuchi, "Fabrication and Characterization of FullereneBased Bulk Heterojunction Solar CELLS with Porphyrin, $\mathrm{CuInS}_{2}$, Diamond and Exciton-Diffusion Blocking Layer," Energies, Vol. 3, No. 4, 2010, pp. 671-685. doi:10.3390/en3040671

[17] T. Oku, T. Noma, A. Suzuki, K. Kikuchi and S. Kikuchi, "Fabrication and Characterization of Fullerene/Porphyrin Bulk Heterojunction Solar Cells," Journal of Physics and Chemistry of Solids, Vol. 71, No. 4, 2010, pp. 551-555. doi:10.1016/j.jpcs.2009.12.034

[18] T. Oku, S. Nagaoka, A. Suzuki, K. Kikuchi, Y. Hayashi, H. Inukai, H. Sakuragi and T. Soga, "Formation and Characterization of Polymer/Fullerene Bulk Heterojunction Solar Cells," Journal of Physics and Chemistry of Solids, Vol. 69, No. 5-6, 2008, pp. 1276-1279. doi:10.1016/i.jpcs.2007.10.117

[19] T. Oku, A. Takeda, A. Nagata, H. Kidowaki, K. Kumada, K. Fujimoto, A. Suzuki, T. Akiyama, Y. Yamasaki and E. Ōsawa, "Microstructures and Photovoltaic Properties of $\mathrm{C}_{60}$ Based Solar Cells with Copper Oxide, $\mathrm{CuInS}_{2}$, Phthalocyanine, Porphyrin, PVK, Nanodiamond, Germanium and Exciton Diffusion Blocking Layers," Material Technology, Vol. 28, No. 1-2, 2013, pp. 21-39. doi:10.1179/1753555712Y.0000000042

[20] K. Yoshida, T. Oku, A. Suzuki, T. Akiyama and Y. Yamasaki, "Fabrication and Characterization of Phthalocyanine $/ \mathrm{C}_{60}$ Solar Cells with Inverted Structure," Advances in Chemical Engineering and Science, Vol. 2, No. 4, 2012, pp. 461-464. doi:10.4236/aces.2012.24056 